\title{
ANALISIS SISTEM PENGENDALIAN INTERNAL PIUTANG USAHA PADA PT. HASJRAT ABADI TOYOTA CABANG MANADO
}

\author{
Sulasry Tahumang ${ }^{1}$, Ventje Ilat ${ }^{2}$, Treesje Runtu ${ }^{3}$ \\ 1,2,3 Jurusan Akuntansi, Fakultas Ekonomi dan Bisnis, Universitas Sam Ratulangi, Jl. Kampus Bahu, Manado, \\ 95115, Indonesia \\ E-mail : srytahumang22@gmail.com
}

\begin{abstract}
ABSTRACK
PT Hasjrat Abadi Toyota Manado Branch is one representative offline from Toyota in North Sulawesi Province and become a representative that sell car in cash or credit in Manado City and make its' agents obtain people to choose for purchasing car in credit, sales credit account will generate receivables in corporate bookkeeping. Accounts receivable commensurate terms or grace period against payment since the surrender of goods trading companies. The purpose of this study to analyze the internal control system receivables at PT Hasjrat Abadi Toyota Manado Branch. Research type in this research is descriptive research. Research's result shows that internal controlling of account receivable in PT Hasjrat Abadi Toyota Manado Branch has been applied well, based on Control Environment, Risk Determination, Control Activities, Communication Information, Supervising and Monitoring. Branch Manager and employees of PT Hasjrat Abadi Toyota Manado Branch supposed to deliberate internal controlling system of account receivables that already perform well and looking for new breakthrough in implementation of system in this dealer.
\end{abstract}

Keywords : internal control system, account receivable.

\section{PENDAHULUAN}

Seiring perkembangan sistem perdagangan sampai dengan saat ini, mekanisme transaksi pembelian barang atau penggunaan jasa telah berubah dari hanya transaksi pembayaran secara langsung menjadi transaksi secara kredit atau tidak secara tunai. Sistem perdagangan barang atau jasa pada awalnya menitik-beratkan pada pemakaian pertukaran sejumlah uang untuk setiap produk atau layanan yang dipergunakan oleh para konsumen untuk memuaskan kebutuhan dan keinginan mereka.

Perkembangan dalam sistem jual beli barang (atau jasa) secara kredit tidak terlepas dari perubahan standar tata cara pelaksanaan sistem transaksi tersebut. Perubahan tersebut pasti berhubungan dengan peraturan yang dibuat dan disahkan oleh pihak pemerintah pusat dan lembaga khusus yang menangani hal tersebut. Di Indonesia, perkembangan sistem penjualan dan pembelian barang (atau jasa) secara kredit, tidak hanya diawasi secara khusus oleh Pemerintah Pusat, tetapi juga oleh Ikatan Akuntan Indonesia (IAI).

Perkembangan perekonomian yang pesat di Indonesia telah menarik perhatian PT Hasjrat Abadi semenjak beberapa dekade yang lalu. Adanya pertumbuhan sosial dan ekonomi di hampir semua daerah di Negara ini merupakan pangsa pasar yang potensial sampai dengan saat ini, dengan tidak melupakan adanya perubahan dalam iklim politik, sosial dan ekonomi yang tidak terduga. Peningkatan tersebut mendorong perubahan status sosial dan ekonomi dari sebagian masyarakat di Indonesia. Salah satu yang menunjukkan hal tersebut adalah pembelian dan penggunaan kendaraan beroda empat oleh masyarakat untuk melakukan interaksi sosial dengan orang lain atau untuk memudahkan dalam melakukan aktivitas penting. Perilaku pembelian ini menjadi dasar penerapan sistem transaksi jual atau beli mobil secara kredit, tanda meniadakan kemungkinan klien membeli unit kendaraan beroda empat 
secara tunai. Dengan diterapkannya sistem transaksi tersebut, pasti terdapat piutang usaha dari klien yang membeli mobil di PT Hasjrat Abadi Toyota Cabang Manado.

Sebagai konsekuensi dari penjualan kredit, maka yang memiliki piutang usaha merupakan asset yang cukup material. Oleh karena itu dibutuhkan manajemen jumlah dana diinvestasikan dalam piutang sesuai dengan tingkat kemampuan perusahaan sehingga tidak mengganggu aliran kas. Pengelolaan piutang pada PT Hasjrat Abadi Cabang Manado belum efektif hal ini dapat dilihat dari data jumlah piutang yang dari akhir tahun 2016 sebesar Rp 964.859.775 dan pada bulan Mei 2017 meningkat menjadi Rp 5.580.134.490 atau meningkat $478,34 \%$. Peningkatan piutang usaha yang sangat besar membutuhkan sistem pengendalian internal yang efektif sehingga tidak akan menjadi kerugian. Berdasarkan uraian tersebut diatas mendorong untuk melakukan penelitian, dengan judul "Analisis Sistem Pengendalian Internal Piutang Usaha Pada PT Hasjrat Abadi Toyota Cabang Manado".

\section{TINJAUAN PUSTAKA}

\subsection{Piutang Usaha}

Sulaeman (2012) menyatakan bahwa piutang usaha (account receivable) timbul akibat adanya penjualan secara kredit agar dapat lebih banyak menjual produk barang dan jasa. Istilah piutang meliputi semua klien dalam bentuk uang terhadap entitas lainnya, termasuk individu, perusahaan atau organisasi lainnya. Dalam kegiatan perusahaan yang normal, biasanya piutang akan dilunasi dalam jangka waktu kurang dari satu tahun sehingga digolongkan dalam aktiva lancar.

Pernyataaan standar akuntan keuangan no. 1 (IAI;2014) mencatat bahwa suatu aktiva diklarifikasikan sebagai aktiva lancar, jika aktiva tersebut:

1. Diperkirakan akan direalisasikan atau dimiliki untuk dijual atau digunakan dalam jangka waktu siklus operasi normal perusahaan.

2. Dimiliki untuk perdagangan atau untuk tujuan jangka pendek dan diharapkan akan direalisasikan dalam jangka waktu 12 (dua belas) bulan dari tanggal neraca atau

3. Berupa kas atau setara kas yang penggunaannya tidak dibatasi.

\subsection{Aktivitas Siklus Penjualan Dan Piutang Usaha}

Menurut Rommey dan Steinbart (2011), sebagaimana dikutip dalam Triandini (2012), siklus penjualan adalah urutan kegiatan sejak diterimanya pesanan dari pembeli, pengiriman barang, penagihan, dan penerimaan kas. Siklus ini melibatkan beberapa bagian dalam perusahaan seperti kredit, gudang, pengiriman dengan tujuan agar penjualan yang terjadi dapat diawasi dengan baik.

Menurut Rommey dan Steinbart (2011), sebagaimana dikutip dalam Triandini (2012), siklus penjualan terdiri dari 4 (empat) poin utama, yaitu:

1. Pemrosesan pesan penjualan

Dalam memproses pesanan penjualan, langkah-langkah yang harus dilakukan adalah:

1) Menerima order dari pelanggan

Pesanan pembelian dapat diterima melalui berbagai cara, surat, email, telepon, atau melalui web. Setelah pemesanan pembelian diproses perusahaan akan menerbitkan pesanana penjualan. Pesanan penjualan memuat informasi mengenai jenis barang yang diminta beserta jumlahnya, harga barang tersebut, dan terms of sale.

2) Memverifikasikan batas kredit

Salah satu cara yang dilakukan untuk memverifikasikan batas kredit adalah memeriksa apakah pelanggan masih mempunyai hutang beredar yang jumlahnya besar. Jika pelanggan masih mempunyai hutang beredar yang jumlahnya besar, maka penjualan harus ditunda atau tidak boleh dilakukan karena akan meningkatkan risiko gagal bayar oleh pelanggan. Selain itu, perusahaan juga harus memeriksa risiko gagal 
bayar oleh pelanggan, apakah dilakukan secara tepat waktu atau sering terlambat karena jika pembayaran sering terlambat, perusahaan harus berpikir dua kali untuk menerima order tersebut karena berpotensi untuk mengganggu arus kas perusahaan.

3) Memeriksa dan mempersiapkan ketersediaan barang

Setelah melakukan verifikasi batas kredit, apabila permohonan kredit pelanggan dipenuhi karena tidak ada masalah baik dalam jumlah hutang dan/atau waktu pembayaran, muka proses pesanan penjualan harus dilanjutkan dengan memeriksa ketersediaan barang. Jika barang tidak tersedia, maka perusahaan harus menginformasikan kepada pelanggan bahwa barang tidak tersedia menggunakan dokumen yang disebut back order.

4) Merespon pertanyaan-pertanyaan pelanggan

Walaupun hanya aktivitas pendukung dalam pemrosesan pesanan penjualan, respon perusahaan terhadap pertanyaan-pertanyaan pelanggan sangatlah penting karena perlu diingat bahwa layanan konsumen yang berkualitas adalah salah satu kunci sukses perusahaan.

2. Pengiriman barang

Jika persediaan yang diminta oleh pelanggan tersedia, maka selanjutnya akan mucul picking ticket. Picking ticket digunakan untuk mengidentifikasi produk dan jumlah persediaan yang akan diambil dari gudang. Untuk meningkatkan efesiensi dan akurasi pergerakkan persediaan, saat ini banyak perusahaan yang telah menggunakan RFID (Radio Frequency Identification). Dengan peggunaan RFID, label yang ada pada persediaan dapat dengan mudahnya direkam saat persediaan keluar dari gedung. Persediaan harus dikemas dengan benar agar saat barang dikirimkan tidak terjadi kerusakan pada barang tersebut. Setelah proses pengemasan, persediaan tersebut akan dikirim ke departemen pegiriman.

Departemen pengiriman harus melakukan pengecekan dengan membandingkan jumlah persediaan yang ada dengan jumlah yang tertera pada picking ticket dan pesanan penjualan. Setelah pengecekan tersebut benar, maka nomor pesanan penjualan, nomor barang, dan jumlah kuantitas dimasukkan kedalam input online. Proses ini akan menghasilkan dokumen slip pengemasan dan bill of lading. Salinan dari slip pengemasan dan bill of lading ini harus disertakan dalam proses pengiriman.

3. Penagihan

Dua aktivitas utama penagihan adalah invoicing dan memperbarui data master piutang. Invoicing adalah aktivitas pemrosesan informasi yang meringkas informasi dari pemrosesan pesanan penjualan dan aktivitas pengiriman. Dokumen dasar yang digunakan untuk menagih pelanggan adalah sales invoice yang memberi tahu jumlah yang harus dibayar. Dua tugas dasar dalam memperbarui data master piutang adalah mendebit piutang ketika sales invoice dikirim dan mengkredit piutang ketika pembayaran diterima.

4. Penerimaan kas

Tahap terakhir dalam siklus penjualan adalah menerima dan memproses pembayaran dari pelanggan.

\subsection{Konsep Pengendalian Internal Menurut COSO}

Committee of Sponsoring Organization of the Treadway Commissi on (COSO) (2013:3) mendefinisikan sistem pengendalian internal adalah sebuah proses yang dilakukan oleh dewan direksi, manajemen dan personil dalam perusahaan yang dirancang untuk memberikan kepastian yang memadai mengenai pencapaian tujuan yang berkaitan dengan operasi, pelaporan dan kepatuhan. COSO memandang pengendalian internal merupakan rangkaian tindakan yang menembus seluruh organisasi. Terdapat lingkungan pengendalian internal menurut COSO (Committee Of Sponsoring Organization), yaitu lingkungan 
pengendalian, penentuan risiko, aktivitas pengendalian, informasi dan komunikasi serta pengawasan pemantuan.

\section{a) Lingkungan pengendalian}

Komponen ini meliputi sikap manajemen disemua tingkatan terhadap operasi secara umum dan konsep pengendalian secara khusus. Hal ini mencakup etika, kompetensi, serta integritas dan kepentingan terhadap kesejahteraan organsasi, juga tercakup struktur organisasi serta kebijakan dan filosofi manajemen.

b) Penentuan risiko

Penentuan risiko merupakan hal yang penting bagi manajemen. Penentuan risiko mencakup penentuan risiko disemua aspek organisasi dan penentuan kekuatan organisasi melalui evaluasi risiko.

c) Aktivitas pengendalian

Komponen ini mencakup aktivitas-aktivitas yang dulunya dikaitkan dengan konsep pengendalian internal. Aktivitas-aktivitas ini meliputi persetujuan, tanggung jawab dan kewenangan, pemisahan tugas, pendokumentasian, rekonsiliasi, karyawan kompoten dan jujur, pemerikasaan internal dan audit internal.

\section{d) Informasi dan komunikasi}

Komponen ini merupakan bagian penting dari proses manajemen. Manajemen tidak dapat berfungsi tanpa informasi. Komunikasi informasi tentang operasi pengendalian internal memberikan substansi yang dapat digunakan manajemen untuk mengevaluasi efektivitas pengendalian dan untuk mengelola operasinya.

e) Pengawasan dan pemantauan

Pengawasan atau pemantuan merupakan evaluasi rasional yang dinamis atas informasi yang diberikan pada komunikasi informasi untuk tujuan manajemen pengendalian. Pemantauan adalah proses yang menentukan kualitas kinerja pengendalian internal sepanjang waktu.

\subsection{Standar Operasional Prosedur}

Kariisma (2014) menyatakan Standart Operating procedure (SOP) adalah serangkaian instruksi kerja tertulis yang di bakukan (terdokumentasi) mengenai proses penyelenggaraan administrasi perusahaan, bagaimana dan kapan harus dilakukan, dimana dan oleh siapa dilakukan.

\subsection{Penelitian Terdahulu}

1. Penelitian yang dilakukan Sulaeman (2012) Siklus penerimaan barang jadi pada PT X telah disajikan secara wajar prosedur evaluasi dan pengujian substantif atas transaksi untuk penjualan dan piutang tidak dilakukan terpisah

2. Penelitian yang dilakukan Nabila Habibie (2013) hasil penelitiannya menunjukkan Secara keseluruhan, pengendalian intern terhadap piutang usaha pada PT.Adira manado berjalan efektif, dimana manajemen perusahaan sudah menerapkan konsep dan prinsip-prinsip pengendalian interen,disisi lain terdapat beberapa prosedur yang belum mencerminkan konsep pengendalian interen.

\section{METODE PENELITIAN}

\subsection{Jenis dan Sumber Data}

Jenis data yang digunakan adalah data kualitatif yaitu metode penelitian yang menjelaskan secara sistematis, faktual dan akurat mengenai sistem pengendalian atas piutang yang dijalankan pada perusahaan tersebut. Sumber data yang diperoleh dalam penelitian ini adalah data primer dan sekunder. 


\subsection{Metode Analisis Data}

Analisis data yang dilakukan dalam penelitian ini adalah dengan metode kualitatif deskriptif. Metode kualitatif deskriptif adalah metode analisis dengan terlebih dahulu mengumpulkan data yang ada kemudian diklarifikasi, dianalisis, selanjutnya diinterprestasikan sehingga dapat memberikan gambaran yang jelas mengenai keadaan yang diteliti. Bentuk analisis yang dimaksud yaitu berdasarkan konsep SOP dan COSO. Didalam SOP yang akan di analisis 3 faktor, yaitu:

1. Deskripsi Piutang

2. Prosedur Piutang

3. Otorisasi pelaporan dan Dokumentasi

Sedangkan konsep pengendalian menurut COSO yang akan di analisis menggunakan 5 komponen, yaitu:

1. Lingkungan pengendalian

2. Penentuan risiko

3. Aktivitas pengendalian

4. Informasi dan komunikasi

5. Pengawasan dan pemantauan

\section{HASIL PENELITIAN DAN PEMBAHASAN}

\subsection{Hasil Penelitian}

\section{Standar Operasional Prosedur (SOP) PT Hasjrat Abadi Toyota Cabang Manado}

Sembilan (9) poin berikut menyatakan hasil analisis penelitian berdasarkan Standar Operasional Prosedur (SOP) untuk PT Hasjrat Abadi Toyota Cabang Manado.

1. Adanya Deskriptif Lengkap Komponen (Sampel) yang harus Dipersiapkan Sebelum Pekerjaan Dilaksanakan di PT Hasjrat Abadi Toyota Cabang Manado

2. Adanya Deskripsi Langka-langka Proses Peristiwa Termasuk Skala atau Kapasitas Operasi

3. Adanya Parameter Pengendalian Proses, Metode dan Keberhasilan

4. Adanya Diagram Alir Kerja

5. Adanya Pengujian Efektivitas

6. Adanya Contoh Perhitungan, Estimasi Waktu, Kartu Isian

7. Adanya Pihak Pelaksana dan yang Bertanggung-jawab

8. Adanya Akuntabilitas Pimpinan

9. Adanya Pelaporan dan Dokumentasi

\section{COSO PT Hasjrat Abadi Toyota Cabang Manado}

Lima (5) poin berikut menyatakan hasil analisis penelitian berdasarkan standar COSO untuk PT Hasjrat Abadi Toyota Manado.

1. Lingkungan Pengendalian PT Hasjrat Abadi Toyota Cabang Manado

PT Hasjrat Abadi Toyota Cabang Manado menerapkan 5 (lima) poin dalam proses pengedalian piutang usaha dari semua pelanggan dealer tersebut, yaitu:

1) Mengutamakan Pelanggan

2) Berintegrasi dalam kerja

3) Prinsip keadilan

4) Sikap profesional

5) Tidak menerima usang dari konsumen

6) Menjaga rahasia perusahaan

7) Team work

2. Penentuan Resiko PT Hasjrat Abadi Toyota Cabang Manado 
PT Hasjrat Abadi Toyota Cabang Manado menentukkan resiko dari setiap pelanggan atau customers yang hendak mengajukan kredit kepemilikkan mobil berdasarkan 3 (tiga) poin berikut, yaitu:

1) Menanda tangani kontrak untuk membayar sesuai dengan tanggal jatuh tempo

2) Validasi kembali tempat kerja, kapasitas dan pendapatan apakah masuk kategori

3) Menjaminkan dokumentasi berharga (BPKB Mobil)

3. Aktivitas pengendalian PT Hasjrat Abadi Toyota Cabang Manado

PT Hasjrat Abadi Toyota Cabang Manado menjalankan sistem pengendalian internal piutang usaha dengan menitik-beratkan pada aktivitas semua karyawan di dealer ini.

4. Informasi Komunikasi PT Hasjrat Abadi Toyota Cabang Manado

PT Hasjrat Abadi Toyota Cabang Manado memastikan sistem pengendalian internal piutang dagang dealer ini telah optimal berdasarkan 3 (tiga) poin berikut, yaitu :

1) Sistem informasi dan manajemen terintegrasi secara online untuk data pelanggan

2) File Komputer yang diakses dan di update secara online untuk data pelanggan

3) Data customer yang diproses dipergunakan untuk pelaporan tiap bula ke departemen kredit dan marketing

5. Pengawasan Dan Pemantauan PT Hasjrat Abadi Toyota Cabang Manado

PT Hasjrat Abadi Toyota Cabang Manado memberikan pertimbangan penting pada 4 (empat) poin penting dalam sub-bagian Pengawasan Dan Pemantauan untuk menjamin sistem pengendalian internal piutang usaha dealaer ini berlangsung secara maksimal, yaitu :

1) Volume penjualan piutang

2) Syarat pembayaran piutang

3) Ketentuan tentang pembatasan piutang maksimal

4) Kebijakan dalam mengumpulkan piutang

\subsection{Pembahasan}

Sistem pengendalian internal piutang usaha merupakan salah satu hal penting dalam menjamin keberhasilan stiap perusahaan pembiayaan dalam megumpulkan keuntungan finansial. Dengan megoptimalkan sistem tersebut, pihak pimpinan dan manajemen, khususnya manajemen marketing, mampu untuk mendapatkan para pelanggan atau customers yang membeli barang secara piutang dan selanjutnya membayarkan angsuran untuk unit yang dibeli secara rutin dan lancar.

PT Hasjrat Abadi Toyota Cabang Manado merupakan salah satu dealer resmi penjualan mobil secara kredit di Kota Manado dan memfokuskan pada merek Toyota. Persaingan yang ketat dalam bisnis kredit kepemilikan mobil membuat dealer ini tidak selamanya mendapatkan closing untuk semua pengajuan kepemilikan mobil yang masuk ke counter sales. Keterlambatan dalam proses pencairan piutang untuk unit mobil dari leasing juga sering menambah catatan piutang dagang yang harus dilaporkan oleh PT Hasjrat Abadi Toyota Cabang Manado.

\subsubsection{Analisis Standar Operasional Prosedur (SOP)}

Pada bagus ini, pembahasan mengenai hasil analisis data yang berkaitan dengan penerapan Standar Operasional Prosedur (SOP) dalam Sistem Pengendalian Internal Piutang pada PT Hasjrat Abadi Toyota Manado diterangkan dengan jelas.

\section{Adanya Deskripsi Lengkap Komponen (Sampel) yang harus Dipersiapkan} sebelum Pekerjaan Dilaksanakan

Informasi awal yang dimiliki calon klien tidak selalu akan mendorong masyarakat untuk membeli suatu barang, termasuk setiap unit mobil dari PT Hasjrat Abadi Toyota Cabang Manado. Poin "Adanya Deskriptif Lengkap Komponen (Sampel) yang harus dipersiapkan sebelum pekerjaan dilaksanakan" memberikan suatu 
keyakinan kepada setiap calon klien atau pembeli di Kota Manado untuk memilih satu unit mobil dari dealer ini dan selanjutnya mengajukan pembelian.

2. Adanya Deskripsi Langkah-langkah Proses Peristiwa Termasuk Skala atau Kapasitas Operasi

Poin "Adanya Langkah-langkah Proses Peristiwa Termasuk Skala atau Kapasitas Operasi" ini menunjukkan bahwa PT Hasjrat Abadi Toyota Cabang Manado mempunyai konsep pelayanan yang jelas dalam proses penjualan mobil secara angsuran dan setiap tahap yang dijalankan memberikan suatu kemudahan dan kepastian bagi masyarakat di Kota Manado untuk membeli Mobil dari Dealer ini.

3. Adanya Parameter Pengendalian Proses, Motode dan Keberhasilan

Poin "Adanya Parameter Pengendalian Proses, Metode dan Keberhasilan" ini adalah penanda bahwa setiap kegiatan operasional yang dilaksanakan oleh para karyawan yang bekerja di PT Hasjrat Abadi Toyota Cabang Manado sudah dilakukan dengan standar pelayanan yang tepat dan terukur, mulai dari proses penjualan dengan angsuran secara keseluruhan, metode pengecekan dan follow-up setiap klien dan pencapaian target dari sales lapangan dan counter sales.

4. Adanya Diagram Aliran Kerja

Poin "Adanya Diagram Aliran Kerja" ini menunjukkan bahwa PT Hasjrat Abadi Toyota Cabang Manado sudah menerapkan pola kerja yang optimal dalam pemberian jasa kepemilikan mobil dengan angsuran kepada masyarakat di Kota Manado dan ditunjukkan dari diagram pengajuan pembelian mobil yang tidak terlalu rumit dan keaktifan para karyawan dealer ini berdasarkan diagram kerja yang termasuk.

5. Adanya Pengajuan Efektivitas

Poin "Adanya Pengajuan Efektivitas" menandakan bahwa PT Hasjrat Abadi Toyota Cabang Manado mempunyai komitmen yang sangat konkrit dalam memberikan pelayanan yang terbaik kepada para klien, mulai dari awal pengajuan pembelian mobil dengan angsuran sampai dengan pengantaran unit mobil yang dipesan kepada klien yang bersangkutan dan pelayanan purna jual dari mobil tersebut.

\section{Adanya Contoh Perhitungan, Estimasi Waktu, Kartu Isian}

Poin “Adanya Contoh Perhitungan, Estimasi Waktu, Kartu Isian" ini memudahkan setiap orang yang hendak membeli mobil dari PT Hasjarat Abadi Toyota Manado mendapatkan alternative yang sesuai mengenai bagaimana perhitungan dana awal dan angsuran setiap bulan yang harus dibayarkannya, perkiraan waktu yang dibutuhkannya untuk melunasi mobil dari formulir-formulir yang wajib untuk diisi dan dilengkapi. Dengan demikian, calon klien tersebut akan memilih untuk membeli mobil di dealer dan meneruskan informasi-informasi penting mengenai hal tersebut kepada keluarga, teman dan kenalannya.

\section{Adanya Pihak Pelaksana dan Yang Bertanggung-jawab}

Dalam setiap perusahaan, para karyawan merupakan salah satu hal penting yang menjamin suatu bisnis akan terus berjalan. Poin "Adanya Pihak Pelaksana dan Yang Bertanggung-jawab" ini menunjukkan bahwa dan bertanggung jawab yang jelas di PT Hasjrat Abadi Toyota Cabang Manado penting dalam penyelesaian setiap pekerjaan yang diberikan kepada masing-masing karyawan, dimana setiap karyawan melaksanakan tugas dan tanggung jawab yang diberikan kepadanya dan memberikan pertanggung-jawaban kepada karyawan dengan posisi yang lebih tinggi.

\section{Adanya Akuntabilitas Pimpinan}

Poin "Adanya Akuntabilitas Pimpinan" ini menunjukkan bahwa pihak pimpinan di PT Hasjrat Abadi Toyota Cabang Manado telah bersifat tegas dan memberikan arahan untuk setiap karyawan dalam bekerja dan diharapkan setiap proses untuk memberikan 
pelayanan kepemilikan mobil kepada masyarakat di Kota Manado akan berjalan dengan baik.

\section{Adanya Pelaporan dan Dokumentasi}

Poin "Adanya Pelaporan dan Dokumentasi" ini mennadakan bahwa sistem pelaporan dan dokumentasi di PT Hasjrat Abadi Toyota Cabang Manado sudah diterapkan dengan efektif dan efisien, sehingga setiap perubahan dalam pencapaian target penjualan mobil secara angsuran dapat dilihat dan dievaluasi oleh pihak pimpinan dan administrasi dealer ini.

\subsubsection{Analisis Sistem Pengendalian Internal Menurut COSO}

Pada bagian ini, pembahasan mengenai hasil analisis data yang berkaitan dengan penerapan standar COSO dalam Sistem Pengendalian Internal Piutang Usaha pada PT Hasjrat Abadi Toyota Cabang Manado diterangkan dengan jelas.

\section{Lingkungan Pengendalian}

Poin lingkungan pengendalian pada PT Hasjrat Abadi Toyota Cabang Manado menunjukkan bahwa sikap manajemen disemua tingkatan terhadap operasi secara umum dan konsep pengendalian secara khusus dari pimpinan dan semua karyawan di dealer ini sudah mencerminkan etos kerja yang baik selama proses pengajuan pembelian mobil secara piutang dan memberikan pelayanan yang terbaik untuk masyarakat di Kota Manado.

\section{Penentuan Resiko}

Poin Penentuan Resiko pada PT Hasjrat Abadi Toyota Cabang Manado menunjukkan bahwa pihak manajemen dari dealer ini telah melaksanakan langkahlangkah yang tepat dalam menetapkan client yang tepat untuk mengurangi piutang tidak tertagih dari PT Hasjrat Abadi Toyota Cabang Manado.

\section{Aktivitas Pengendalian}

Poin Aktivitas Pengendalian pada PT Hasjrat Abadi Toyota Cabang Manado menunjukkan bahwa dealer ini telah memberikan tugas dan tanggung jawab untuk semua orang yang bekerja, mulai dari pimpinan sampai dengan cara karyawan. Pembagian tugas dan tanggung jawab yang jelas untuk setiap karyawan menjadikan pihak pimpinan dan manajemen PT Hasjrat Abadi Toyota Cabang Manado mampu mengantur kegiatan operasional yang berlangsung dengan baik, khususnya pekerjaan yang dilaksanakan oleh setiap karyawan di dealer ini. Hasil tersebut berjalan dengan kesimpulan dari mokoginta (2015) yang menyatakan bahwa aktivitas pengendalian yang dilakukan terhadap sistem informasi akuntansi juga sudah memadai. Perusahaan (yang analisis) telah melaksanakan pemisahan tugas yang jelas pada fungsi-fungsi terkait. Setiap transaksi dan aktivitas perusahaan juga telah di otorisasi pegawai yang berwenang, dokumen-dokumen yang digunakan dan setiap transaksi tersebut mempunyai nomor urut tercetak sehingga dokumen tersebut sudah memadai dalam menciptakan aktivitas pengendalian.

\section{Informasi Komunikasi}

Poin informasi Komunikasi pada PT Hasjrat Abadi Toyota Manado menunjukkan bahwa pencatatan dan pelaporan dari semua data penjualan secara piutang telah dicatat dalam sistem yang terkomputerisasi dan bisa diakses dengan muda. Hal ini menjadi data penjualan piutang tersebut dapat dilihat oleh pihak manajemen dari PT Hasjrat Abadi Toyota Cabang Manado, dealer lain dari PT Hasjrat Abadi Toyota dan kantor pusat PT Hasjarat Abadi Toyota. Hasil penelitian ini sesuai dengan kesempulan dari sulaeman (2012) yang menyatakan bahwa informasi dan komunikasi mengenai piutang usaha telah diterapkan cukup efektif, baik informasi 
yang disampakan oleh pihak manajemen kepada bawahannya maupun informasi yang berasal dari karyawan kepada manajemen.

\section{Pengawasan dan Pemantauan}

Poin Pengawasan dan Pemantauan pada PT Hasjrat Abadi Toyota Cabang Manado menunjukkan bahwa pihak manajemen dari dealer ini telah menetapkan dasar yang dapat diterima dalam volume pemberian piutang kepemilikan mobil, syarat pembayaran piutang, pembatasan piutang dan cara pengumpulan piutang yang sesuai dengan kondisi keuangan dari masing-masing client. Hasil tersebut sejalan dengan kesimpulan dari Mokoginta (2015) yang menyatakan bahwa aktivitas pemantuan terhadap penegendalian internal sistem informasi akuntansi telah berjalan dengan baik dan efektif. Hal ini dibuktikan dengan realitas yang ada dimana aktivitas perusahaan (yang dianalisis) telah berjalan dengan baik.

\subsubsection{Analisis Piutang}

Pada bagian ini, pembahasan mengenai hasil analisis data yang berkaitan dengan proses terjadinya dan pertumbuhan piutang dalam Sistem Pengendalian Internal Piutang Pada PT Hasjrat Abadi Toyota Cabang Manado diterapkan dengan jelas.

\subsubsection{Analisis Umum}

Dari penjelasan hasil analisis penelitian dibagian sebelumnya, didapatkan hasil akhir bahwa PT Hasjrat Abadi Cabang Toyota Manado telah mampu menerapkan sistem pengendalian internal piutang dengan baik, walaupun terdapat beberapa penyesuaian dalam penerapan sistem tersebut secara langsung. Petugas analisis berkas membutuhkan waktu yang lama untuk mencairkan piutang leasing ke PT Hasjrat Abadi Toyota Cabang Manado akibat terlambatan pembayaran angsuran mobil customer ke leasing merupakan salah satu contoh penyesuaian dalam sistem pengendalian ini. Karena penyesuaian tersebut seringkali tidak langsung komunikasikan ke pihak manajemen, bisa saja terjadi hal yang mempersulit PT Hasjrat Abadi Toyota Cabang Manado dalam proses penagihan angsuran piutang mobil. koordinator yang lebih baik diantara setiap karyawan yang bekerja di PT Hasjrat Abadi Toyota Manado merupakan hal penting dalam mempertahankan sistem pengendalian internal piutang dagang di dealer ini, atau bahkan meningkatkan kualitas pelaksanaannya.

\section{KESIMPULAN DAN SARAN}

\subsection{Kesimpulan}

Sistem pengendalian internal piutang usaha pada PT Hasjrat Abadi Toyota Cabang Manado telah diterapkan dengan baik, berdasarkan Lingkungan Pengendalian, Penentuan Resiko, Aktivitas Pengendalian, Informasi Komunikasi dan Pengawasan Dan Pemantauan.

\subsection{Saran} adalah :

Berdasarkan hasil penelitian dan kesimpulan yang telah diterangkan sebelumnya

1. Pimpinan dan para karyawan PT Hasjrat Abadi Toyota Cabang Manado harus memperhatikan penerapan sistem pengendalian internal piutang usaha yang sudah berjalan dengan baik, agar supaya dealer ini akan lebih baik lagi dalam beroperasi di tahun-tahun mendatang.

2. Pimpinan dan para karyawan PT Hasjrat Abadi Toyota Cabang Manado harus mencari terobosan baru dalam penerapan sistem pengendalian internal piutang usaha di dealer ini, agar supaya dealer ini akan lebih optimal dalam memberikan jasa perkreditan kepada masyarakat di Kota Manado. 


\section{DAFTAR PUSTAKA}

Alifa, Rizza Nur. 2013. Implementasi Pengendalian Internal Pemberian Kredit Dana Tunai Pada Perusahaan Pembiayaan. (Studi Kasus pada PT. Nusa Surya Ciptadana Finance Cabang Salatiga). Kertas Kerja Akhir, Program Studi Akuntansi, Fakultas Ekonomi Dan Bisnis, Universitas Kristen Satya Wacana, Salatiga.

Committee of Sponsoring Organizations of the Treadway Commission (COSO). 2013.

Gyebi, Francis dan Samuel Quain. 2013, Internal Control on Cash Collection. A Case Of the Electricity Company of Ghana Ltd,Accra East Region. International Journal of Business and Social Science, Vol. 4 No. 9; August 2013.

Halonen, Patteri. 2014. Risk-Based Evaluation of Internal Controlsin Case Company's Sales Process-Case Company X. Thesis. Departement of Accounting, Aalto Universuty, School of Business.

Hayati, Rosda. 2013. Analisis Faktor-Faktor Yang Mempengaruhi Pemberian Kredit Sepeda Motor Yamaha Pada PT. BAF (Bussan Auto Finance) Cabang Bangkinang. Skripsi. Jurusan Manajemen, Fakultas Ekonomi Dan Ilmu Sosial, Universitas Islam Negeri Sultan Syarif Kasim, Riau.

Hery. 2016. Akuntansi: Aktiva, Utang, dan Modal, Cetakan Pertama, Edisi kedua, Jakarta: Gava Media.

Ikatan Akuntan Indonesia 2017. Standar Akuntansi keuangan, Jakarta: Salemba Empat.

Mulyadi. 2014. Auditing. Jakarta, Salemba Empat.

Nabila Habibie. 2013. Analisis Pengendalian Intern Piutang Usaha Pada PT Adira Finance Cabang Manado

PT Hasjrat Abadi (www.hasjrat.co.id)

Romney, Marshall B., Steinbart, Paul J. 2011. Accounting Information System $12^{\text {th }}$ ed. New Jersey: Pearson Education.

Rimbano, Dheo. 2015. Diktat/Modul/Buku Ajar Mata Kuliah Metodologi Penelitian, Sekolah Tinggi Ilmu Ekonomi Musi Rawas (STIE - MURA) Lubuklinngau

Sulaeman.2012. Analisis Prosedur Pengendalian Intern Piutang Usaha Pada Astra Credit Companies Cabang Makassar. Skripsi. Fakultas Ekonomi Dan Bisnis, Jurusan Akuntansi, Universitas Hasanuddin.

Triadini, Ayu Anggita. 2012. Prosedur Audit Atas Siklus Penjualan Barang Jadi Pada PT X. Laporan Magang Fakultas Ekonomi, Program Studi Akuntansi, Universitas Indonesia, Depok.

Yunita, Asri. 2012 Analisis Piutang Pasien Rawat Jalan Dengan Penjamin Perusahaan Dan Asuransi Di Rumah Sakit Islam Jakarta Cempaka Putih Periode Tahun 2010. Tesis. Fakultas Kesehatan Masyarakat, Program Studi Pasca Sarjana, Kajian Administrasi Rumah Sakit, Universitas Indonesia, Depok. 